\title{
ANALISIS DEFORMASI GALIAN DALAM PADA TITIK TEPI DINDING DIAFRAGMA DENGAN METODE ELEMEN HINGGA MELALUI STUDI EVALUASI MODEL TANAH
}

\author{
Hadianti Muhdinar Pasaribu \\ Dosen Pengajar Program Studi Teknik Sipil, Fakultas Teknik, UMSU, Medan \\ Surel : hadiantimp@gmail.com \\ Diterima : 16 April 2018; Disetujui : 28 Mei 2018
}

\begin{abstract}
ABSTRAK
Banyaknya pembangunan infrastruktur yang merupakan salah satu tolak ukur kemajuan suatu daerah menyebabkan terjadinya penyempitan lahan didaerah tersebut. Sehingga pemanfaatan ruang dan lahan sangat dibutuhkan untuk menunjang kemajuan pesatnya pembangunan infrastruktur. Salah satu inovasi terbaik dalam mengatasi masalah keterbatasan lahan adalah membuat bangunan bawah tanah sehingga memberi ruang yang lebih untuk pembangunan. Pembangunan yang cukup terbaru di Indonesia saat ini adalah pembangunan MRT (Mass Rapid Transit) yang dilakukan di Jakarta. Pembangunan ini dalam pelaksanaannya membutuhkan proses konstruksi terowongan (tunneling) dan galian dalam untuk tiap stasiunnya. Pada penelitian ini, penulis terpusat terhadap masalah galian dalam pada stasiun Senayan dari proyek konstruksi MRT Jakarta. Permasalahan terbesar dalam suatu pekerjaan galian dalam adalah adanya deformasi lateral pada dinding bangunan bawah tanah dalam hal ini yang digunakan adalah dinding diafragma (D-Wall) dan juga adanya penurunan tanah disekitar galian. Oleh karena itu, perlu dilakukan pengecekan agar tidak terjadi keruntuhan. Metode konstruksi yang digunakan pada stasiun Senayan adalah metode konstruksi TopDown. Pada penelitian ini dilakukan analisis deformasi horizontal dan penurunan tanah menggunakan software Plaxis 3D dengan dua pemodelan tanah, yaitu model tanah Mohr Coulomb dan Hardening Soil. Hasil deformasi horizontal yang diperoleh menggunakan model tanah Hardening Soil lebih mendekati monitoring dilapangan dibandingkan dengan model tanah Mohr-Coulomb. Penelitian ini berfokus pada bagian-bagian tepi pada dinding diafragma melengkapi jurnal sebelumnya yang berfokus pada titik tengah dari dinding diafragma. Besarnya deformasi horizontal pada tahap akhir galian (penimbunan kembali tanah hingga dasar muka tanah) di titik P\#80 (di tepi dinding diafragma) tercatat pada monitoring inclinometer sebesar $4.15 \mathrm{~mm}$, dan deformasi yang dihasilkan menggunakan model Hardening Soil sebesar $9.57 \mathrm{~mm}$ sedangkan menggunakan model Mohr-Coulomb sebesar $16.05 \mathrm{~mm}$. Hasil deformasi horizontal yang diperoleh menggunakan model tanah Hardening Soil lebih mendekati monitoring dilapangan dibandingkan dengan model tanah MohrCoulomb meskipun hasil yang diperoleh cukup jauh dari monitoring dilapangan.
\end{abstract}

Kata Kunci : Galian Dalam, Deformasi Horizontal, Model Mohr Coulomb, Model Hardening Soil, Plaxis $3 \mathrm{D}$

\begin{abstract}
The number of infrastructure development which is one of the benchmarks of the progress of a region causes the narrowing of land in the area. So that the utilization of space and land is needed to support the rapid progress of infrastructure development. One of the best innovations in overcoming the problem of land limitations is to make the underground building giving more space for development. The most recent development in Indonesia today is the construction of MRT (Mass Rapid Transit) conducted in Jakarta. This development in its implementation requires tunneling and deep trenching process for each station. In this study, the authors centered on the deep trenching problems at the Senayan station from the Jakarta MRT construction project. The biggest problem in a deep trenching work is the lateral deformation of underground building walls in this case which is used diaphragm wall (D-Wall) and also the decrease of soil around the excavation. Therefore, it is
\end{abstract}


necessary to check to avoid collapse. The construction method used in Senayan station is a Top-Down construction method. In this research, horizontal deformation and soil degradation analysis using Plaxis 3D software with two soil modeling, Mohr Coulomb and Hardening Soil soil model. The result of the horizontal deformation obtained using Soil Hardening Soil model is closer to monitoring the field compared to the MohrCoulomb soil model. This study focuses on the edges of the diaphragm wall complementing the previous journal focusing on the midpoint of the diaphragm wall. The magnitude of the horizontal deformation at the final stages of excavation (backfill) to $P$ \# 80 (on the edge of the diaphragm wall) was recorded in inclinometer monitoring of $4.15 \mathrm{~mm}$, and the resulting deformation using the Hardening Soil model of $9.57 \mathrm{~mm}$ while using the Mohr model -Coulomb of $16.05 \mathrm{~mm}$. The horizontal deformation results obtained using the Soil Hardening Soil model is closer to the field monitoring than the Mohr-Coulomb soil model although the results obtained are quite far from the field monitoring.

Keywords: Deep Excavation, Horizontal Deformation, Mohr Coulomb Model, Hardening Soil Model, Plaxis $3 D$.

\section{Pendahuluan}

Pembangunan konstruksi bawah tanah dengan pekerjaan galian dalam pada proyek MRT Jakarta di Stasiun Senayan yang menjadi lokasi penelitian ini menggunakan perkuatan dinding diafragma. Metode konstruksi yang digunakan dalam pelaksanaannya adalah metode top down, dengan 3 tahapan penggalian dan pemasangan slab permanen saat pengerjaan konstruksi dilakukan. Kedalaman desain galian berada di level $17.208 \mathrm{~m}$ dengan panjang stasiun $200 \mathrm{~m}$ dan lebar $21.3 \mathrm{~m}$ untuk bagian tepi dan 19. $3 \mathrm{~m}$ untuk bagian tengah.

\section{Kajian Pustaka}

\subsection{Prilaku Galian Dalam}

Penggunaan konstruksi galian semakin banyak diminati dengan meningkatnya tingkat kebutuhan manusia saat ini. Oleh karena itu, dibutuhkan suatu konsep kestabilan galian untuk mengatasi masalah keruntuhan galian. Untuk mencapai tujuan tersebut, diperlukan suatu pemahaman terhadap faktor-faktor yang berhubungan dengan keruntuhan galian dan metode perkuatan galian yang efektif.

Dalam menjaga kestabilan galian, maka dapat dilakukan galian tanpa perkuatan dinding penahan tanah dan galian dengan perkuatan dinding penahan tanah. Galian tanpa perkuatan dinding penahan tanah merupakan suatu galian dengan membuat kemiringan tertentu terhadap bidang horizontal. Namun, metode ini sulit diterapkan pada daerah perkotaan akibat keterbatasan lahan yang ada. Sehingga digunakan metoda galian dengan perkuatan dinding penahan tanah untuk menjaga kestabilan galian. Galian akan menjadi stabil jika kuat geser tanah lebih besar dibandingkan dengan kuat geser yang diperlukan. Hal yang penting dilakukan dalam menganalisis galian adalah melakukan penyelidikan kondisi tanah yang akan digali dan juga perlu diketahui bagaimana perilaku galian dalam tersebut.

Dalam mekanika tanah terdapat dua hal penting yang perlu dianalisis yaitu keruntuhan geser tanah yang dapat menyebabkan gangguan pada strukur dan deformasi yang dapat mendorong tekanan yang sangat besar pada struktur. Secara umum desain struktur penahan seharusnya mempertimbangkan halhal sebagai berikut : keseimbangan momen pada sistem (overturning), keseimbangan gaya horisontal (sliding), keseimbangan arah vertikal (bearing capacity), overstress dari struktur (bending atau shearing) dan stabilitas tanah disekitar struktur (slope failure, overall stability, basal stability).

\subsection{Pergerakan Horizontal}

Kekakuan sistem support yang terdiri dari sistem dukungan arah lateral (strut, anchor), sistem dukungan arah vertikal (wall system, anchor) dan sistem dukungan untuk menahan lentur (wall system). Setiap sistem support tersebut memiliki komponen yang menentukan bentuk dan besarnya lendutan yang terjadi. Menurut Clough dan O'Rourke (1990), ratarata defleksi horisontal maksimum dinding di lempung kaku (stiff clay), tanah residual dan pasir adalah sekitar 0,2\% kedalaman galian, tetapi ada kasus dimana besarnya adalah sekitar $0,5 \%$ atau lebih. Tidak ada perbedaan yang signifikan diantara tipe dinding yang ditunjukkan pada Gambar 1 dibawah ini. 


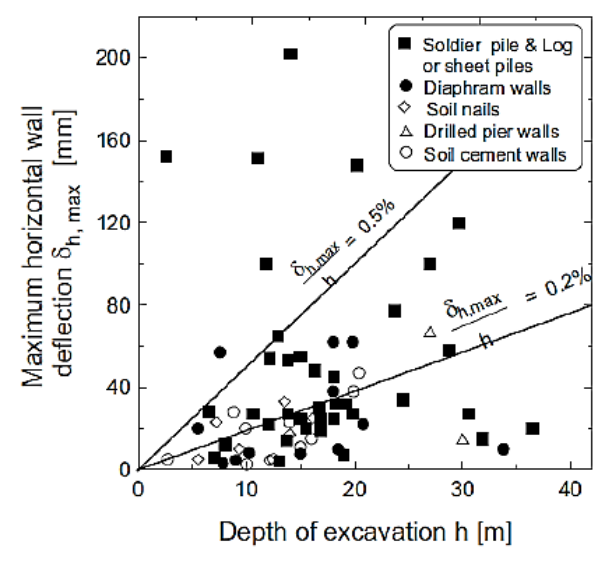

Gambar 1. Pengamatan Defleksi Horizontal Maksimum Dinding Untuk TipeTipe Dinding Pada Tanah Lempung Kaku (Stiff Clay), Tanah Residual, Dan Pasir (Clough Et Al, 1990)

\section{Studi Kasus}

Studi kasus yang digunakan dalam penelitian ini adalah pembangunan Stasiun Senayan MRT Jakarta. Pada penelitian ini dilakukan simulasi numerik dengan software Plaxis 3D. Model konstitutif tanah yang digunakan adalah model Mohr Coulomb dan Hardening Soil. Dalam melakukan pemodelan tanah dan analisis maka diperlukan data tanah. Data tanah didapatkan dari hasil pengeboran uji SPT pada titik BH E-480. Setelah dilakukan stratigrafi dan soil profiling maka didapatkan profil tanah. Kemudian dilakukan interpretasi data untuk mendapatkan parameter tanah yang dibutuhkan untuk pemodelan dan input pada software Plaxis 3D.

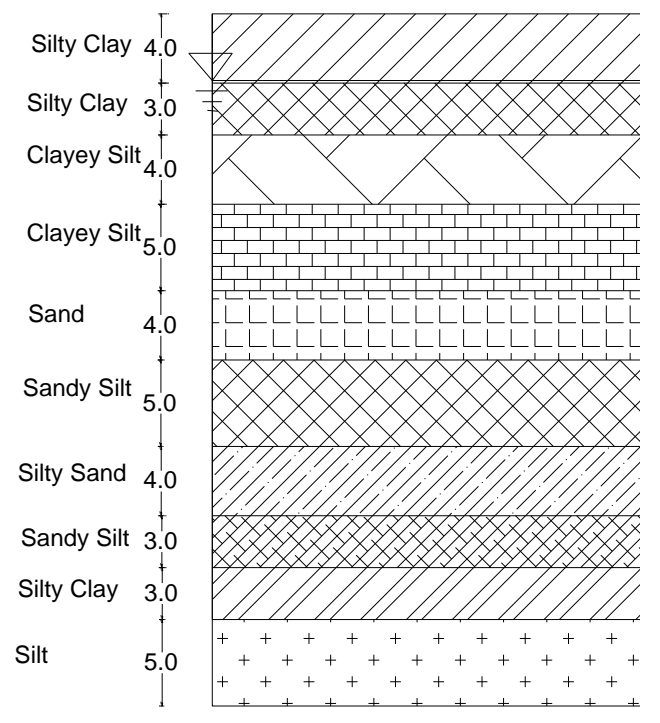

Gambar 2. Profil Tanah Yang Mewakili

\subsection{Analisa Pengujian Propertis Batu Bata}

Metode analisis yang digunakan dalam studi kasus ini dapat dilihat pada Tabel 1 dibawah ini:

Tabel 1. Metode Analisis Drained Dan Undrained

\begin{tabular}{|c|c|c|c|}
\hline \multirow{2}{*}{ Material Model } & \multirow{2}{*}{ Metode } & \multicolumn{2}{|c|}{ Parameter } \\
\cline { 3 - 4 } & & Strength & Stiffness \\
\hline \multirow{2}{*}{ Mohr-Coulomb } & Undrained A & $\mathrm{c}^{\prime}$ dan $\phi^{\prime}$ & $\mathrm{E}^{\prime}$ dan $v^{\prime}$ \\
\cline { 2 - 4 } & Drained & $\mathrm{c}^{\prime}$ dan $\phi^{\prime}$ & $\mathrm{E}^{\prime}$ dan $v^{\prime}$ \\
\hline \multirow{2}{*}{ Hardening Soil } & Undrained A & $\mathrm{c}^{\prime}$ dan $\phi^{\prime}$ & $\mathrm{E}^{\prime}$ dan $v^{\prime}$ \\
\cline { 2 - 4 } & Drained & $\mathrm{c}^{\prime}$ dan $\phi^{\prime}$ & $\mathrm{E}^{\prime}$ dan $v^{\prime}$ \\
\hline
\end{tabular}

Kedalaman galian stasiun Senayan ini adalah $17.208 \mathrm{~m}$, dengan panjang $200 \mathrm{~m}$ dan lebar 23.3 $\mathrm{m}$ untuk sisi pinggir dan lebar $19.3 \mathrm{~m}$ pada sisi tengah. Kedalaman instalasi Diaphragm wall (DWall) yang dilakukan adalah $22.927 \mathrm{~m}$.

Tahapan konstruksi yang dilakukan adalah sebagai berikut:

1) Pemasangan konstruksi D-Wall dan pembebanan pada permukaan tanah sebelum dilakukan galian yang merepresentasikan pembebanan dari alatalat berat yang bekerja disekitar lokasi galian dalam, beban yang diberikan sebesar $10 \mathrm{kN} / \mathrm{m} 2$ dalam jangkauan $20 \mathrm{~m}$ pada tiap sisi kiri dan sisi kanan daerah galian.

2) Pemasangan pressure relief well (PRW) yang difungsikan untuk mengurangi tekanan air pori yang terjadi pada lapisan tanah yang berlapis-lapis. Pada Plaxis, PRW dimodelkan sebagai tanah granuler linear elastic dengan diameter ukuran 20 $\mathrm{cm}$.

3) Galian tahap 1, galian dilakukan hingga level roof slab pada elevasi $-2.898 \mathrm{~m}$.

4) Pengecoran roof slab setebal $0.8 \mathrm{~m}$ dan pemberian beban sebesar $13 \mathrm{kN} / \mathrm{m} 2$ yang merepresentasikan beban dari kegiatan pekerjaan alat berat diatas roof slab, beserta penimbunan backfill setebal $0.75 \mathrm{~m}$ di atas roof slab.

5) Pemasangan kingpost dengan jarak $5 \mathrm{~m}$ hingga level concourse slab.

6) Galian tahap 2, galian dilakukan hingga level concourse slab pada elevasi $-8.598 \mathrm{~m}$. Sebelum dilakukan penggalian, muka air pada daerah penggalian diturunkan terlebih dahulu.

7) Pengecoran concourse slab dengan tebal 0.4 $\mathrm{m}$ dan pemberian beban sebesar $5 \mathrm{kN} / \mathrm{m} 2$ pada slab.

8) Pemasangan kingpost dengan jarak $5 \mathrm{~m}$ hingga level akhir penggalian. 
9) Galian tahap 3, galian dilakukan hingga level akhir penggalian (FEL) pada elevasi -17.208 m. Sebelum dilakukan penggalian, muka air pada daerah penggalian diturunkan terlebih dahulu.

10) Pengecoran base slab dengan tebal $1 \mathrm{~m}$.

11) Penimbunan kembali backfill hingga level muka tanah.

Berikut Tabel Resume parameter tanah dan struktur yang digunakan dari Tabel 2 hingga Tabel 5 dibawah ini:

Tabel 2. Resume Parameter Model Tanah MohrCoulomb

\begin{tabular}{|c|c|c|c|c|c|c|c|c|c|c|c|c|c|c|c|c|c|c|}
\hline & \multirow{2}{*}{ Kedalaman } & & \multirow{2}{*}{$N_{\text {thererda }}$} & \multirow{2}{*}{ Konsistensi } & Yonst & lst & $c_{u}$ & $\phi$ & $c^{\prime}$ & $\phi$ & PI & $k x$ & ky & $\beta$ & & & \multirow{2}{*}{\begin{tabular}{|c}
$\mathrm{Eu}$ \\
$\left(\mathrm{kN} / \mathrm{m}^{2}\right)^{2}$
\end{tabular}} & \\
\hline & & & & & $\left|\left(\mathrm{kN} / \mathrm{m}^{3}\right)\right|$ & $\left|\left(k N / m^{3}\right)\right|$ & $\left|\left(k P_{a}\right)\right|$ & (9) & $\mathrm{kN} / \mathrm{m}^{2} \mid$ & (9) & $\%$ & $(\mathrm{~m} / \mathrm{s})$ & $(\mathrm{m} / \mathrm{s})$ & $(-)$ & & & & \\
\hline 1 & 4 & \begin{tabular}{|l|l|}
4 & Silty Cla
\end{tabular} & 8 & Soft to Medium & \begin{tabular}{|l|l|}
15.2 \\
\end{tabular} & 16.2 & \begin{tabular}{|l|l|}
48.0 \\
\end{tabular} & 0 & 9.6 & 20 & 48 & $1.00 E-07$ & $1.00 E-07$ & 0 & 0.35 & 0.45 & 8640 & 7776 \\
\hline 2 & 4 & Silty $\mathrm{Cl}_{2}$ & 9 & Medium & | 15.5 & 16.5 & 54.0 & 0 & 10.8 & 21 & \begin{tabular}{|l|l}
47 \\
\end{tabular} & \begin{tabular}{|l|l|}
$1.00 E-07$ \\
\end{tabular} & $1.00 E-07$ & 20 & 0.35 & 0.45 & 10800 & 9720 \\
\hline 3 & 1 & \begin{tabular}{l|l|}
11 & Clayey S
\end{tabular} & 11 & Medium to Stiff & \begin{tabular}{|l|l|}
16.5 \\
\end{tabular} & 17.5 & 666.0 & 0 & 13.2 & 21 & 45 & $1.00 E-07$ & $1.00 E-07$ & 7300 & 0.35 & 0.45 & \begin{tabular}{|l|}
19800 \\
\end{tabular} & 17820 \\
\hline 4 & 16 & \begin{tabular}{|l|l|}
6 & Clayey S
\end{tabular} & 19 & Stiff & \begin{tabular}{|l|l|}
177.0 \\
\end{tabular} & 18.0 & 114.0 & 0 & 222.8 & 22 & 39 & \begin{tabular}{|l|l}
$1.00 E-07$ \\
\end{tabular} & $1.00 E-07$ & 7250 & 0.35 & 0.45 & 28500 & 25650 \\
\hline 5 & $16 \cdot-20$ & Sand & 35 & Dense & \begin{tabular}{|l|l|}
18.0 \\
\end{tabular} & 19.0 & - & & 0 & 37 & 0 & $1.00 E-05$ & $1.00 E-05$ & & 0.3 & 0.3 & . & 70000 \\
\hline 6 & 25 & \begin{tabular}{|l|l|}
55 & Sandy
\end{tabular} & 50 & $\begin{array}{l}\text { Very Hard } \\
\end{array}$ & \begin{tabular}{|l|l|}
177.9 \\
\end{tabular} & 18.9 & 300.0 & 0 & 60 & 23 & 34 & $1.00 E-07$ & $1.00 E-07$ & 7400 & 0.35 & 0.45 & 120000 & 108000 \\
\hline 7 & 29 & \begin{tabular}{|l|l|l}
29 & Silty San
\end{tabular} & 40 & Very Dense & \begin{tabular}{|l|l|}
18.0 \\
\end{tabular} & 19.0 & & & 5 & 37 & 0 & 1 1.00E-06 & $1.00 E-06$ & & 0.3 & 0.3 & - & 80000 \\
\hline 8 & 32 & \begin{tabular}{|l|l|}
2 & Sandy \\
\end{tabular} & 48 & $\begin{array}{l}\text { Hard } \\
\text { and }\end{array}$ & \begin{tabular}{|l|}
177.3 \\
\end{tabular} & 18.3 & 288.0 & 0 & 57.6 & 24 & 28 & $1.00 E-07$ & $1.00 E-07$ & 7400 & 0.35 & 0.45 & 115200 & 103680 \\
\hline 9 & 35 & \begin{tabular}{l|l}
55 & Silty Clz
\end{tabular} & 31 & $\begin{array}{l}\text { Very Stiff } \\
\end{array}$ & \begin{tabular}{|l|l|}
177.0 \\
\end{tabular} & 18.0 & 186.0 & 0 & 37.2 & 23 & 30 & $\begin{array}{l}1.00 E-07 \\
\end{array}$ & $1.00 E-07$ & & 0.35 & 0.45 & 61380 & 55242 \\
\hline 10 & $35 .-40$ & Silt & 33 & $\begin{array}{l}\text { Very Stiff } \\
\end{array}$ & \begin{tabular}{|l|l|}
17.5 \\
\end{tabular} & 18.5 & 198.0 & 0 & 39.6 & 23 & 30 & $1.00 E-07$ & $1.00 E-07$ & & 0.35 & 0.45 & 69300 & 62370 \\
\hline
\end{tabular}

Tabel 3. Resume Parameter Model Tanah Hardening Soil

\begin{tabular}{|c|c|c|c|c|c|c|c|c|c|c|c|c|c|c|c|c|c|}
\hline & \multirow{2}{*}{\multicolumn{2}{|c|}{$\frac{\text { Kedalaman }}{(\mathrm{m})}$}} & \multirow[b]{2}{*}{ Tipe Tanah } & \multirow[b]{2}{*}{$N_{\text {Etatarata }}$} & \multirow[b]{2}{*}{ Isistensi } & & \multirow{2}{*}{\multicolumn{2}{|c|}{\begin{tabular}{l|l}
$\phi$ & $\mathrm{c}^{\prime}$ \\
of & $\left(\mathrm{N} / \mathrm{m}^{2}\right)$
\end{tabular}}} & \multirow{2}{*}{\begin{tabular}{|l|}
$\phi$ \\
19 \\
\end{tabular}} & \multirow[b]{2}{*}{$v_{u}$} & & \multirow[b]{2}{*}{\begin{tabular}{|l|}
$(-)$ \\
\end{tabular}} & \multirow{2}{*}{ 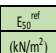 } & \multirow{2}{*}{\begin{tabular}{|l|}
$\mathrm{E}_{0 \mathrm{ede}}$ \\
$\left(\mathrm{kN} / \mathrm{m}^{2}\right)$ \\
\end{tabular}} & \multirow{2}{*}{ 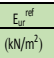 } & \multirow{2}{*}{\begin{tabular}{|c|}
$\mathrm{m}$ \\
(power)
\end{tabular}} & \\
\hline & & & & & & & & & & & & & & & & & \\
\hline & 0.1 & 4 & Slay & & Med & 48.0 & & 9.6 & & 0.45 & 0.35 & 30 & 7776 & \begin{tabular}{|l|}
6221 \\
\end{tabular} & 23328 & 85 & 0.8 \\
\hline & & & & & & & & & & 5 & & & & & 100 & & 0.8 \\
\hline & & 11 & & & & & & & & 0.45 & 0.35 & 00 & & & & & \\
\hline & & 16 & & & & & & & & 0.45 & 0.35 & 250] & 50 & 20 & 76950 & & \\
\hline 5 & $\overline{16}$ & 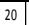 & & & & & & & & 0.3 & 0.3 & & 00 & 56000 & 210000 & .5 & 0.5 \\
\hline 6 & 20 & 25 & & & & & & & 5 & 0.45 & 0.35 & 4000 & 108000 & 86400 & 324000 & 82 & 0.82 \\
\hline & 25 & 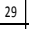 & & & & & & & 37 & \begin{tabular}{|l|}
0.3 \\
\end{tabular} & 0.3 & & 000 & 64000 & 240000 & 55 & 0.5 \\
\hline & & 3 & & & & & & & & 5 & & & & & & & \\
\hline 9 & 32 & 35 & & 31 & & & & & & 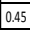 & & . & & 44194 & & & 0.8 \\
\hline 10 & & 40 & & & & 30 & & & 13 & 10 & 0.35 & & 2370 & $4989 \mathrm{C}$ & 871. & & \\
\hline
\end{tabular}

Tabel 4. Parameter Struktur Yang Digunakan Pada Plaxis 3D

\begin{tabular}{|l|c|c|c|c|c|c|}
\hline \multirow{2}{*}{ Nama Plate } & \multirow{2}{*}{ Tipe } & $\mathrm{d}$ & $\gamma$ & $\mathrm{E}_{1}$ & \multirow{2}{*}{$v_{12}$} & $\mathrm{G}_{12}$ \\
\cline { 3 - 5 } & & $(\mathrm{m})$ & $\left(\mathrm{kN} / \mathrm{m}^{3}\right)$ & $\left(\mathrm{kN} / \mathrm{m}^{2}\right)$ & & $\left(\mathrm{kN} / \mathrm{m}^{2}\right)$ \\
\hline D-Wall & Elastic & 1 & 24 & $2.80 \mathrm{E}+07$ & 0.2 & $1.17 \mathrm{E}+07$ \\
\hline Roof Slab & Elastic & 0.8 & 24 & $2.80 \mathrm{E}+07$ & 0.2 & $1.17 \mathrm{E}+07$ \\
\hline Concourse Slab & Elastic & 0.4 & 24 & $2.80 \mathrm{E}+07$ & 0.2 & $1.17 \mathrm{E}+07$ \\
\hline Base Slab & Elastic & 1 & 24 & $2.80 \mathrm{E}+07$ & 0.2 & $1.17 \mathrm{E}+07$ \\
\hline
\end{tabular}

Tabel 5. Parameter Kingpost

\begin{tabular}{|l|c|c|c|}
\hline $\begin{array}{c}\text { Nama Fixed End } \\
\text { Anchor }\end{array}$ & Tipe & $E A$ & $\mathrm{~L}_{\text {spacing }}$ \\
\cline { 3 - 4 } & & $(\mathrm{kN})$ & $(\mathrm{m})$ \\
\hline King Post & Elastic & $1.80 \mathrm{E}+07$ & 5 \\
\hline
\end{tabular}

Dari parameter tanah dan struktur yang digunakan diperoleh Generate Mesh menggunakan Program Plaxis 3D seperti pada Gambar 3 dibawah ini.

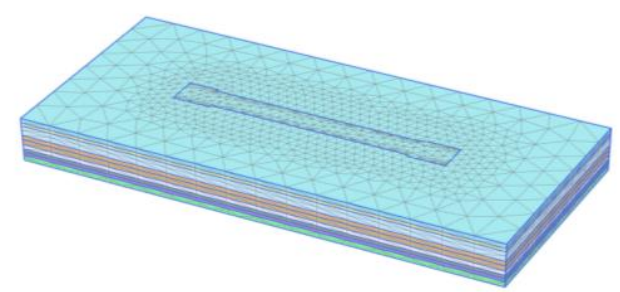

Gambar 3. Generate Mesh Plaxis 3D

4 Hasil dan Pembahasan

4.1 Deformasi Horizontal

Deformasi horizontal yang diperoleh berdasarkan permodelan tanah Mohr Coulomb dan Hardening Soil pada Plaxis 3D, hasilnya kemudian dibandingkan dengan titik monitoring dilapangan, titik yang dipilih adalah titik pada bagian tepi dinding yaitu titik P\#3, P\#80 dan P\#37.

Titik-titik monitoring dapat dilihat pada Gambar 4 dibawah ini:

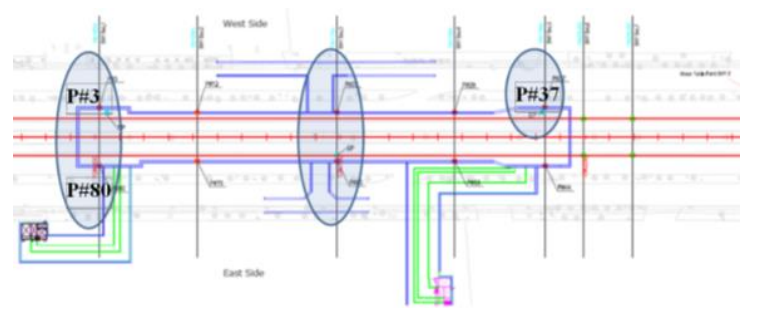

Gambar 4. Monitoring Plan Stasiun Senayan Jakarta (Data monitoring MRT, 2015)

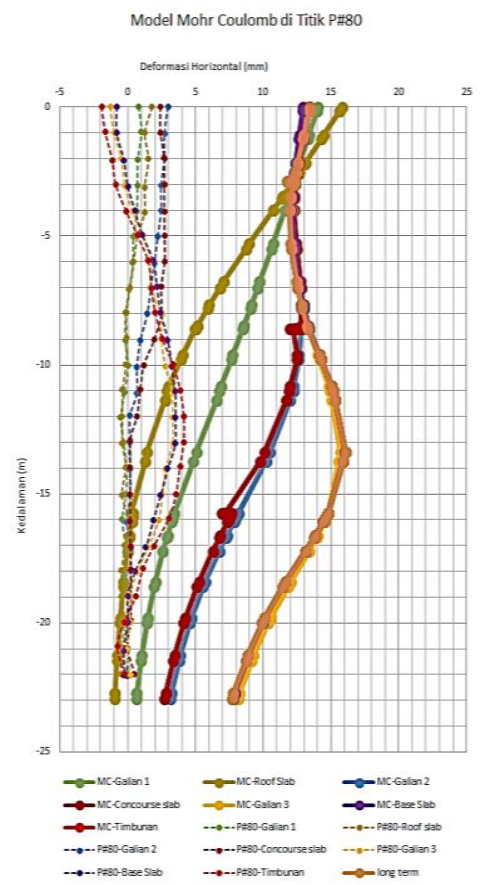

(a) 


\section{Analisis Deformasi Galian Dalam Pada Titik Tepi Dinding Diafragma Dengan Metode Elemen Hingga Melalui Studi Evaluasi Model Tanah}

Model Mohr Coulomb di Titik P\#3

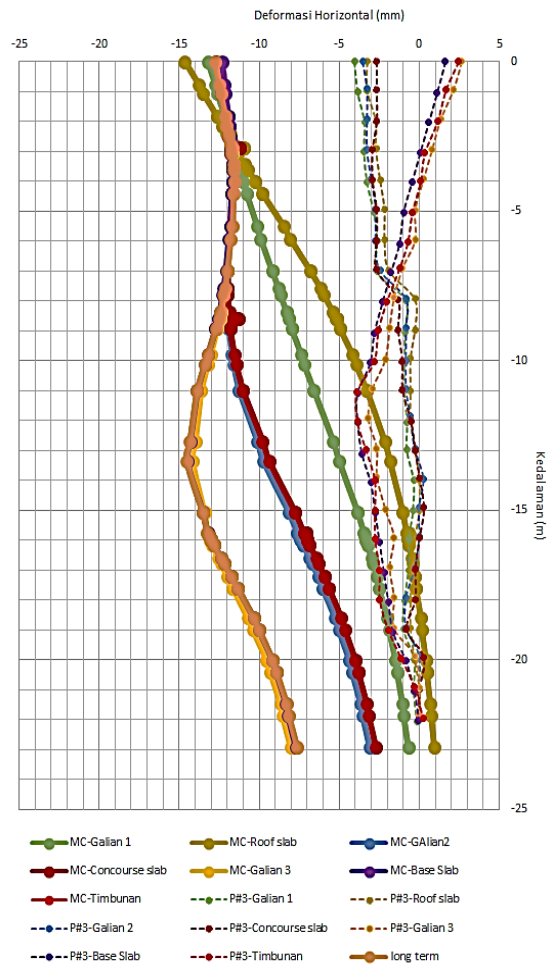

(b)

Gambar 5. (A) Deformasi Horizontal Model Mohr-Coulomb Di P\#3 Dan (B) Deformasi Horizontal Model Mohr-Coulomb Di P\#80

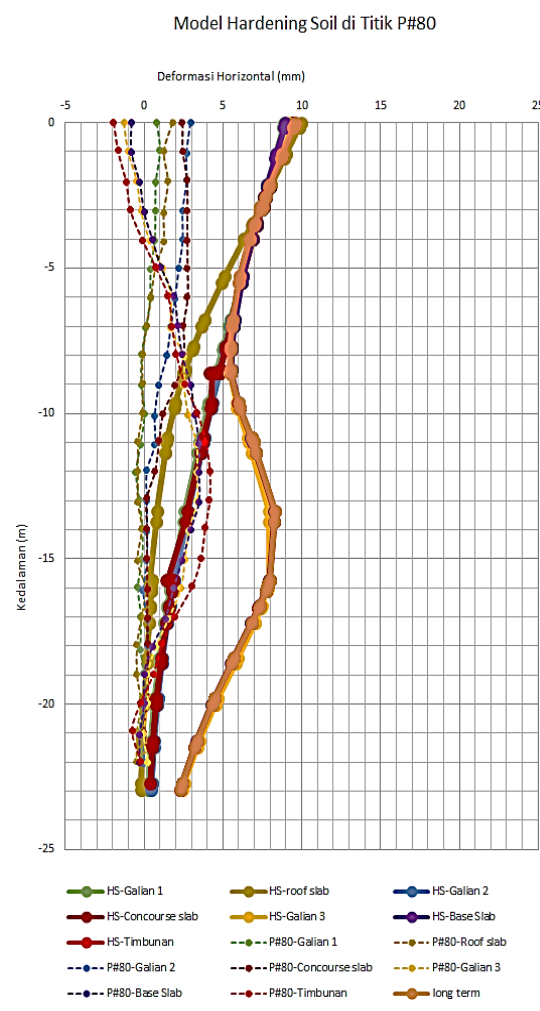

(a)
Model Hardening Soil di Titik P\#3

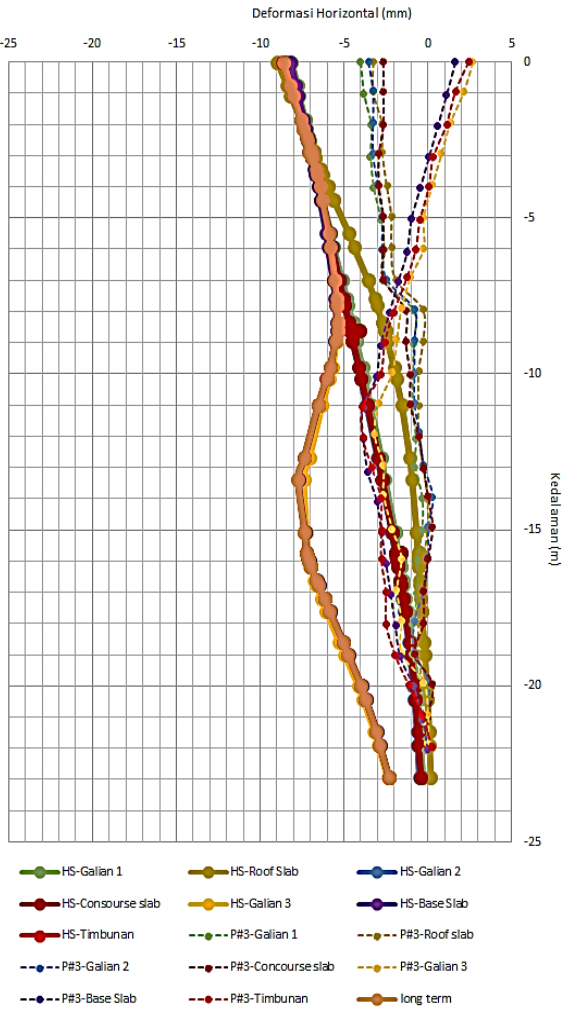

(b)

Gambar 6. (a) Deformasi Horizontal Model Hardening Soil Di P\#3 Dan (B) Deformasi Horizontal Model Hardening Soil Di P\#80

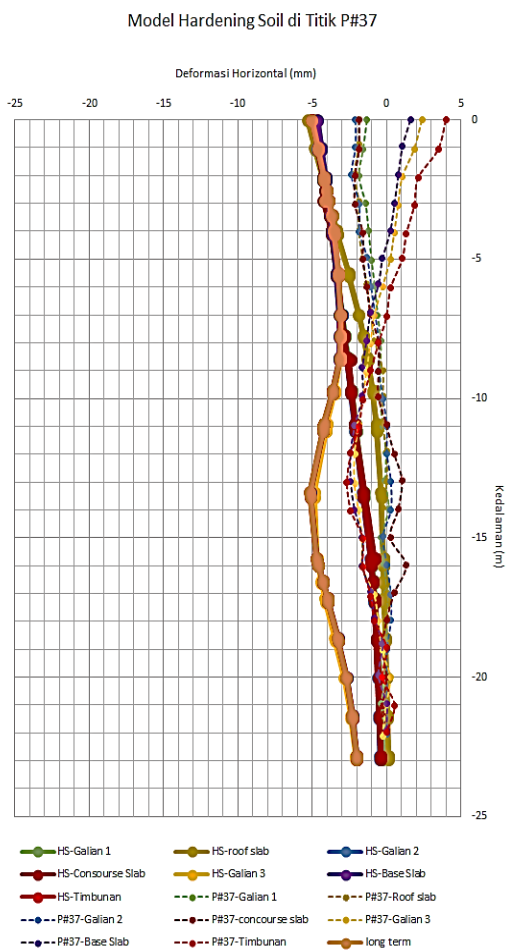

(a) 


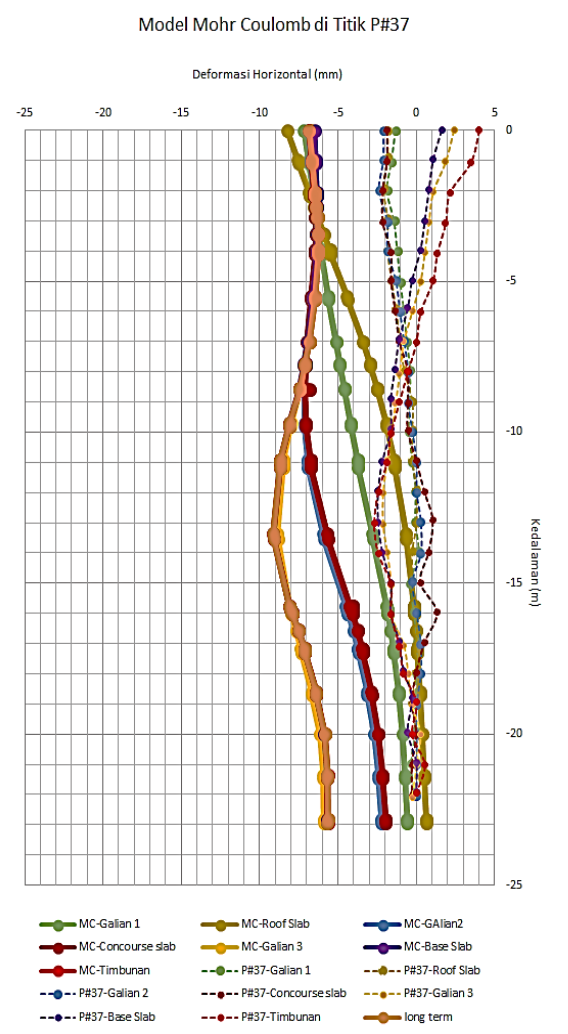

(b)

Gambar 7. (a) Deformasi Horizontal Model Mohr Coulomb Di P\#37 Dan (B) Deformasi Horizontal Model Hardening Soil Di P\#37

Besarnya deformasi horizontal maksimum yang terjadi pada tahapan konstruksi galian dalam pada permodelan tanah Mohr-Coulomb dan Hardening Soil dapat dilihat pada gambar 8 berikut.

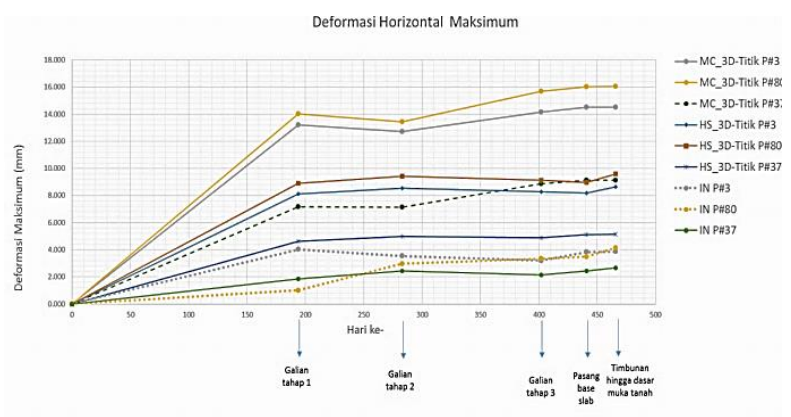

Gambar 8. Deformasi Horizontal Maksimum

\subsection{Pembahasan}

Nilai deformasi horizontal yang dihasilkan menggunakan permodelan tanah Hardening Soil lebih kecil dan mendekati hasil monitoring di lapangan daripada menggunakan model tanah Mohr-Coulomb.

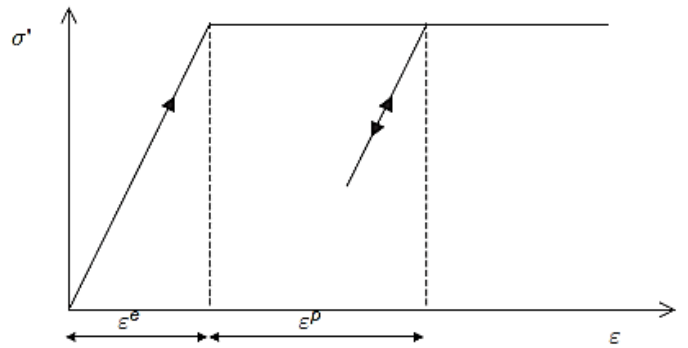

(a)

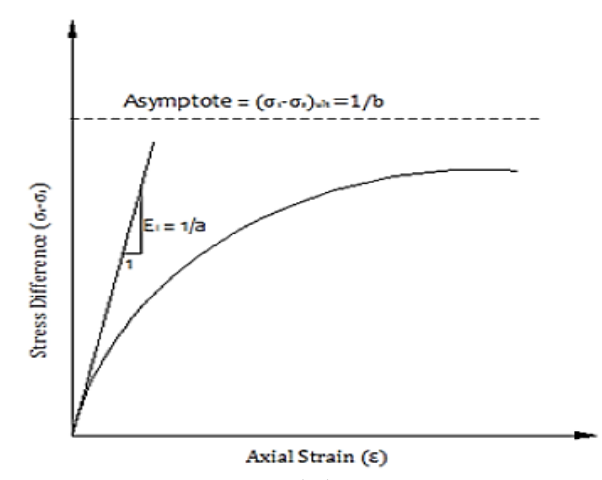

(b)

Gambar 9. Hubungan Tegangan-Regangan (A) Model Mohr Coulomb (Manual Plaxis) (B) Model Hardening Soil (Duncan \& Chang, 1970)

Hal ini sesuai dengan kondisi pendekatan model Hardening Soil yang lebih mendekati perilaku tanah dilapangan dibandingkan dengan model Mohr Coulomb. Kurva hubungan stress-strain pada model Hardening Soil membentuk kurva hiperbolik yang menunjukkan perubahan nilai modulus elastisitasnya yang berbeda dan cenderung mengecil seiring dengan perubahan tegangan yang diberikan pada tanah. Keadaan ini lebih mendeskripsikan kondisi sebenarnya di lapangan.

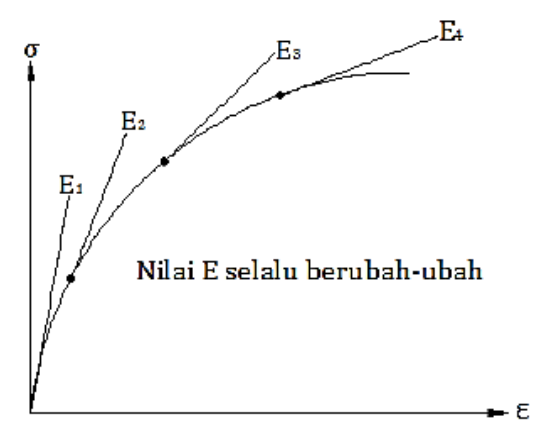

Gambar 10. Perilaku Tanah Sesungguhnya (Liong, 2013) 


\section{Analisis Deformasi Galian Dalam Pada Titik Tepi Dinding Diafragma Dengan Metode Elemen Hingga Melalui Studi Evaluasi Model Tanah}

Akibat metode konstruksi yang digunakan pada pekerjaan galian dalam adalah metode top down, sehingga menyebabkan deformasi yang terjadi saat kondisi drained tidak jauh berbeda daripada saat akhir tahapan konstruksi. Hal ini terjadi karena metode top down menggunakan langsung slab permanen saat konstruksi berlangsung sehingga mengunci pergerakan dinding diafragma. Selain itu, karena jenis tanah disekitar galian cukup kuat dengan nilai $\mathrm{N}$-spt yang cukup tinggi maka deformasi yang terjadi juga tidak terlalu besar.

\section{Simpulan}

Dari penelitian yang sudah dilakukan pada stasiun Senayan MRT Jakarta, maka dapat ditarik kesimpulan sebagai berikut.

1) Besarnya deformasi horizontal yang diperoleh menggunakan model tanah Hardening Soil secara umum lebih mendekati dengan hasil monitoring dilapangan dibandingkan dengan model tanah Mohr-Coulomb.

2) Besarnya deformasi maksimum yang terjadi pada tiap tahap konstruksi galian dalam dengan menggunakan model Hardening Soil menunjukkan hasil deformasi yang lebih kecil daripada model Mohr-Coulomb pada Plaxis 3D.

3) Deformasi yang dihasilkan pada bagian tepi dinding diafragma lebih kecil dibandingkan dengan pada bagian tengah dinding, namun deformasi yang dihasilkan cukup besar sehingga perlu untuk diperhatikan.

\section{Daftar Pustaka}

Bishop, A.W. dan Bjerrum, L. (1960): The Relevance of the Triaxial Test to the Solution of Stability Problems, ASCE Conference on Strength of Cohesive soils, pp 437 - 501.

Bowles, Joseph E. (1982): Foundation Analysis and Design, Third Edition, Mc. Graw-Hill Companies, Inc. New York.

Das, Braja M. (2011): Principles of Foundation Engineering, 7th Edition, Thomson Learning, Inc.

Holtz, Robert D., William D. Kovacs, Thomas C. Sheahan. (2011): An Introduction Geotechnical Engineering Second Edition, Pearson Education, Inc.

Kempfert, Hans-Georg dan Gebreselassie, Berhane. (2006): Excavations and Foundations in Soft Soils, SpringerVerlag Berlin Heidelberg.

Lim, A., Ou., C. Y., \& Hsieh, P. (2010): Evaluation of clay constitutive models for analysis of deep excavation under undrained conditions, Journal of Geoengineering, Vol. 5, No. 1.

Ou, Chang-Yu. (2006): Deep Excavation Theory and Practice, London. Taylor \& Francis Group. London.

Ou, Chang Yu dan Ching-Her Lai. (1993): Finite-Element Analysis of Deep Excavation in Layered Sandy and Clayey Soil Deposits, Can. Geotech. 1, 31, 204-214. China.

Sorensen KK, dan Okkels N. (2013): Correlation Between Drained Shear Strength and Plasticity Index of Undisturbed Overconsolidated Clays, Journal of 18th International Conference on Soil Mechanics and Geotechnical Engineering, Paris.

Y. M. Hou, J. H. Wang, dan L. L. Zhang. (2009): Finite-Element Modeling of a Complex Deep Excavation in Shanghai, Acta Geotechnica 4:7-16, Springer-Verlag. 